\title{
ARTICLE \\ Study on the Suitability of Soils in Ilu Aba Bora Zone for Hydraform Block Production for Low Cost Construction
}

\section{Beneyam Neguse Furgasa* Fadilu Shafi Jote Natnael Bekele Tilahun}

Department of Construction Technology and Management, College of Engineering and Technology, Mettu University, Mettu, Ethiopia

\section{ARTICLE INFO}

Article history

Received: 26 April 2021

Accepted: 6 May 2021

Published Online: 15 May 2021

\section{Keywords:}

Hydra form block

Compressive strength

Cost comparison

Cement

Water absorption

\begin{abstract}
Due to high construction material cost in Ethiopia, it is difficult to afford a shelter for most people. The hydra form block (HFB) has been identified as lowcost building material with its potential and possibility to reverse the housing problem. Laboratory tests were conducted on Mettu, Nopa, Gore, and Hurumu areas soil. Using hydra form machine with average mold size of $29 * 14 * 10$ $\mathrm{cm}$, hydra form blocks were cast with the three percentages increment of cement. Compressive strength and water absorption tests were conducted at 28 day. The investigation has revealed that all the soil sample except Gore soil have significant characteristics that make it suitable for stabilization with recommended soil properties. From the experimental study, all the blocks except blocks produced with Gore soil have 28th day compressive strength values well above most of the recommended minimum values. Water absorption was less than the maximum limit of $15 \%$. But, for control block and for stabilized with $3 \%$ cement, water absorption result is out of the recommended values $(0-15) \%$. The cost comparison of hydra form blocks with hollow concrete block and fired clay brick shows that the hydra form block is cheapest walling material in terms of production cost and a typical hydra form block production center can create jobs for more than 50 people.
\end{abstract}

\section{Introduction}

Due to material cost and many other reasons, Basic needs mainly shelter is a main problem of most the people, especially for those living in developing countries like Ethiopia. Nowadays many researchers focus on and searching for an alternative, low cost and environmentally friendly construction material. As stated by ${ }^{[1]}$, currently a lot of studies mainly focuses on searching for new or modified alternative construction material. Also as reported by ${ }^{[2]}$, in most of developing countries, only $10 \%$ of population increases per year was afforded the house. As a building material Hydra form blocks have a lots of advantages including but not only: it create a job, since it is lesser cost it is affordable and offer good opportunity to construct a house by low income people, since it is produced locally mostly on site it is easy to control quality and enhance building quality and also it also solve the

*Corresponding Author:

Beneyam Neguse Furgasa,

Department of Construction Technology and Management, College of Engineering and Technology, Mettu University, Mettu, Ethiopia;

Email:Binicotm07@gmail.com 
problem of foreign currency shortage which is headache of developing countries ${ }^{[3]}$. The major disadvantage of using earth without any stabilization was it is durability. As stated by ${ }^{[3]}$, durability is strongly related to compressive strength and soil by nature also have limited strength, have no good dimensional stability and less durable due to many reasons as compared to other building construction material. However, this limitation of soil was improved by stabilizing with material like cement and proper compaction.

\section{Materials and Methodology}

\subsection{Material}

Soil: The soil used in this research was Mettu, Nopa, Hurrumu, and Gore area soil, which is located in Ilu Aba Bora zone.

Cement: Ordinary Portland Cement (OPC) available on market.

Water: Drinkable water (potable water) was used.

\subsection{Data Collection}

The sandy soil sample was taken from four woredas (Gore, Nopa, Hurumu and Mettu woredas) in Ilu Aba Bora zone, with the help of woredas technical person from woredas water and mining office. The experimental test was conducted at Jimma University, Jimma Institute of Technology soil laboratory and GIA Engineering PLC in Addis Ababa, Ethiopia.

\subsubsection{Preparation of Soil Sample for Hydra Form Block Production}

It is only after soil identification has been done, with the results being acceptable, that subsequent procedures including extraction, may follow. The soil was extracted manually using shovels from the sub-soil level (from about $0.5 \mathrm{~m}$ downwards from the surface). Soil preparation after extraction involves drying out, temporary storage, pulverization, stockpiling and screening. Storing and stockpiling simply follow the key operations of drying and pulverization. The extracted soil was dried out by spreading it out in thin layers on a hard level surface. Pulverization and breaking up of soil lumps was done by hand tools (wooden hammers) which help speed up the drying process. The pulverized soil was screened which was done by sieving.

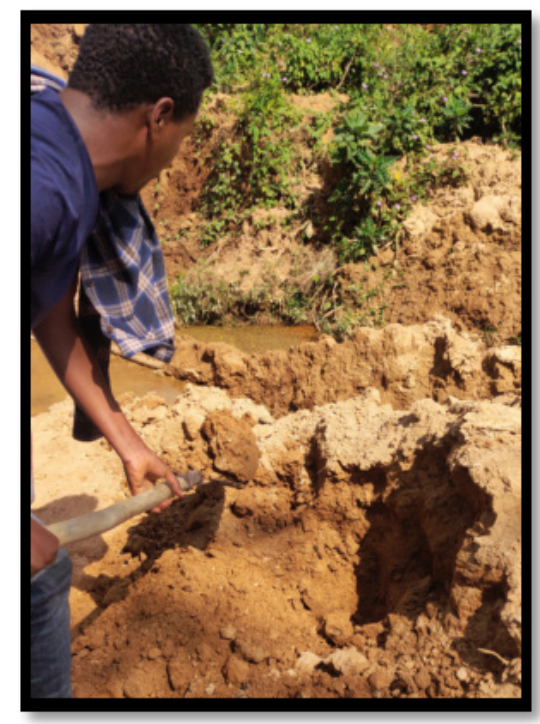

Figure 1. Soil extraction from quarry

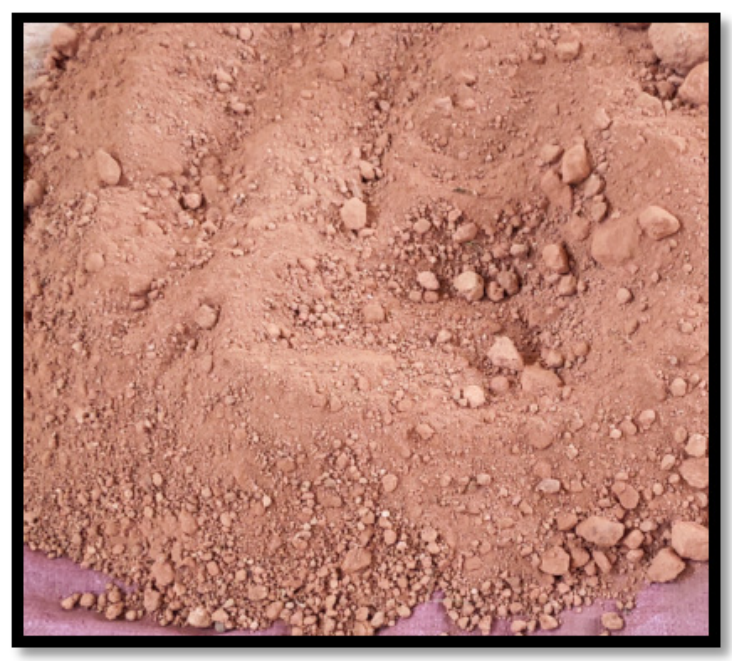

Figure 2. Preparation of the soil

\subsubsection{Mix Preparation and Casting of Blocks}

Since the preparation of specimens was considered to be one of the most important stages in the execution of the experiments, extra care had been taken with the soil stabilizers mix, compression, curing, and sizing of the samples. According to ${ }^{[4]}$ the most commonly employed full compressed earth blocks have molding dimensions of $29 \mathrm{~cm} *$ $14 \mathrm{~cm} * 10 \mathrm{~cm}$. In this study blocks were produced using a hydra form machine having mold of this dimension. The production process comprises batching, mixing, casting and compaction of the blocks. The batching method used in this study was weight batching method, with the predetermined percentages of stabilization $(0 \%, 3 \%, 6 \%$, $9 \%$ and $12 \%$ ). The required quantity of soil sample was measured and spread using a shovel to a reasonably large

DOI: https://doi.org/10.30564/jbms.v3i1.3156 
surface area. Cement was then spread evenly on the soil and mixed thoroughly with the shovel. The dry mixture was spread again and water was added gradually while mixing, until the optimum moisture content of the mixture was attained, when the soil breaks into 4 or 5 parts, the water is considered right. Then the pre-weighed soil stabilizers mix was carefully poured into the HF machine, then compressing it firmly. The blocks were then carefully removed and put over base plates, and immediately placed on a flat surface and left to cure in the shade.

\subsubsection{Curing of Blocks}

In primary curing phase (immediately after the de-molding of blocks), the blocks were shielded from direct sunlight and strong winds using plastic sheeting for five days and during the secondary curing, was done by dry stacking the blocks under a covered shed for the remaining 23 days to protect stabilized blocks from direct sunlight, wind and rain.

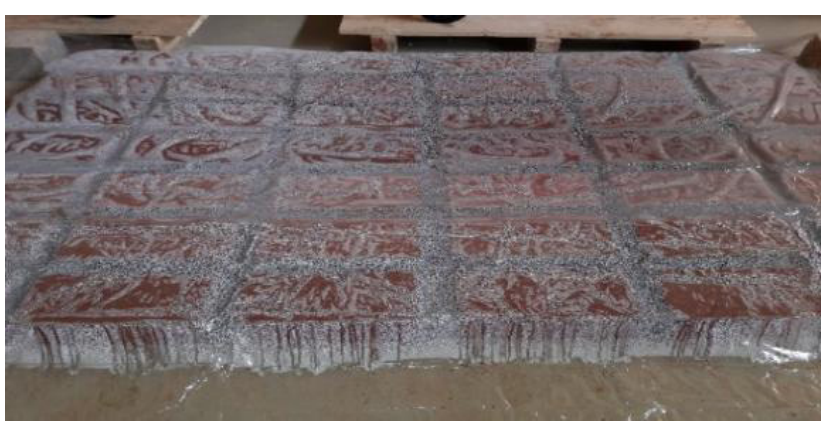

Figure 3. Curing with plastic sheet

\subsubsection{Hydra Form Block Compressive Strength and Water Absorption Test}

The blocks were tested for compressive strength at the ages of 28 day, six blocks for each stabilization percentage including the control mix. The weight of the each block was measured before being placed on the compression testing machine and then crushed. The corresponding failure load was recorded. The crushing force was divided by the sectional area of the block to arrive at the compressive strength. The water absorption was performed by taking five blocks from each group (mix) at the specified age, and weighing them on a balance. These blocks were then immersed completely in water for 24 hours, after which they were removed and weighed again. The percentages of water absorbed by the blocks were estimated as follows:

$\mathrm{TWA}=[(\mathrm{WS}-\mathrm{WD}) / \mathrm{WD}] \times 100$, Where: TWA $=$ Total water absorption (\%), WS = weight of soaked block, WD $=$ weight of dry block 


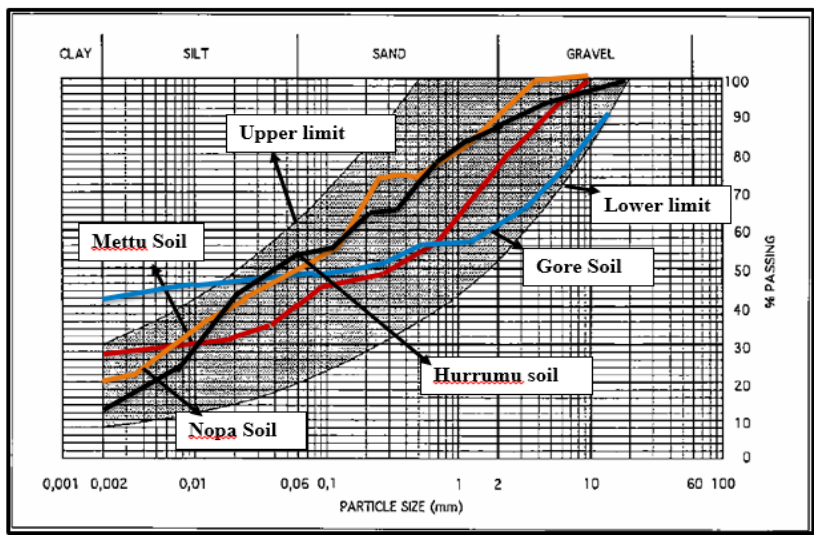

Figure 6. Particle size distribution of the sample soil on the diagram of Texture

\section{Atterburg Limit}

Table 1. Atterburg limit test results of soil sample from Mettu, Nopa and Hurrumu, and Gore

\begin{tabular}{ccccc}
\hline \hline $\begin{array}{c}\text { Atterburg limits } \\
\text { Value }\end{array}$ & Mettu(1) & Gore(2) & Nopa(3) & Hurrumu(4) \\
\hline Liquid limit, \% & 32.2 & 42.31 & 27 & 39.42 \\
Plastic limit, \% & 24 & 23.3 & 16.1 & 23 \\
Plasticity index,\% & 8.2 & 19.01 & 10.9 & 16.42 \\
\hline
\end{tabular}

The plasticity index and liquid limit of Mettu soil were 8.2 and 32.2 respectively, 19.01 and 42.31 for Gore soil, 10.9 and 27 for Nopa soil, 16.42 and 39.42 for the Hurrumu soil respectively. Based on these results we can check the suitability of the sample soil for hydra form block production. The soil sample is checked for suitability in the plasticity diagram of standard ${ }^{[4]}$. As shown in Figure 4 , the result reviled that all the soil sample falls in the shaded region of Standard as shown in Figure 7, which indicates that all soil sample was suitability for the hydra form block production.

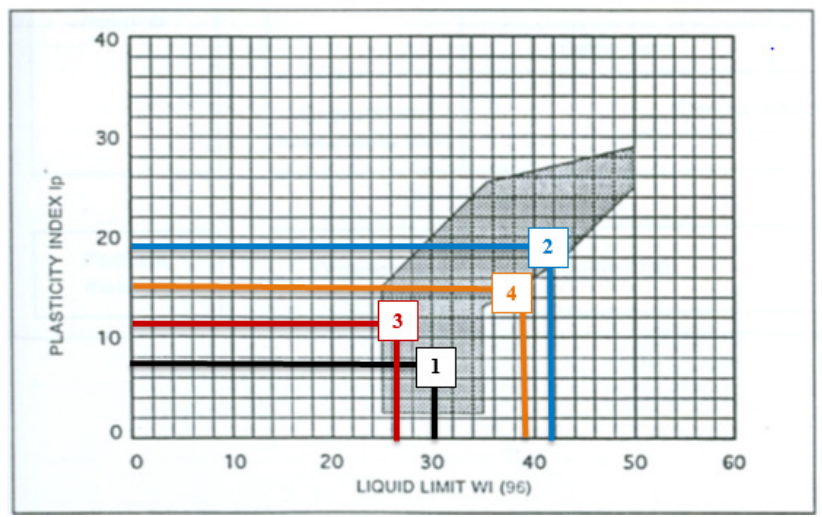

Figure 7. Diagram of Plasticity

\section{Soil Compaction Test}

Since all the soil samples have been checked of its liquid limits and plasticity index for the soil suitability for the production of hydra form block and the result shows it fulfill the standard and it imply that further test id required to check it is compaction tests. While the soil is compressed or compacted the air voids between the soil particles were removed, as a result the compressive strength of the block was improved or increased. The soil compaction test or proctor test was expressed in terms of the optimum moisture content and the soil maximum dry density. Standard proctor tests for the soils from Mettu, Nopa, Hurrumu, and Gore soil have been determined by using ASTM D 698, and the results shows that, for Mettu soil the maximum dry density (MDD) and optimum moisture content (OMC) of the soil was $17.4 \mathrm{kN} / \mathrm{m}^{3}$ and $17.5 \%$ respectively, for Gore soil the maximum dry density (MDD) and optimum moisture content (OMC) of the soil was $15.4 \mathrm{kN} / \mathrm{m}^{3}$ and $29 \%$ respectively, for Nopa soil the maximum dry density (MDD) and optimum moisture content (OMC) of the soil was $15.32 \mathrm{kN} / \mathrm{m}^{3}$ and $23 \%$ respectively and for Hurumu soil the maximum dry density (MDD) and optimum moisture content (OMC) of the soil was $17.2 \mathrm{kN} / \mathrm{m}^{3}$ and $19 \%$ respectively.

The amount of compaction is the primary factor affecting maximum dry density and optimum moisture content for a given soil type. In this particular case compaction of the soil samples were conducted by using M7-00-199 Hydraform making machine using $10 \mathrm{MPa}$ system pressure. The optimum moisture content was determined by using the ideal block length for a given soil type. The amount of moisture content used to produce this ideal block length is taken as optimum moisture content. The ideal block length was nearly $29 \mathrm{~cm}$ and the amount of water required to get this length was $25 \%$.

\subsection{Compressive Strength}

Table 2. Mean compressive strength of Hydra form block

\begin{tabular}{cccccc}
\hline \multirow{2}{*}{$\begin{array}{c}\text { 28th Day Mean } \\
\text { Compressive Strength } \\
(\mathrm{MPa})\end{array}$} & \multicolumn{5}{c}{ Cement Content in (\%) } \\
\cline { 2 - 6 } & 0.785 & 1.16 & 2.068 & 3.217 & 4.358 \\
\hline Mettu & 0.636 & 0.855 & 1.137 & 2.017 & 2.478 \\
Gore & 0.8325 & 1.387 & 2.578 & 3.45 & 4.6 \\
Nopa & & & & & \\
& 0.66 & 1.36 & 2.718 & 3.72 & 4.496 \\
\hline
\end{tabular}

DOI: https://doi.org/10.30564/jbms.v3i1.3156 
The compressive strength increased with increasing cement content. This is due to the fact that the cement hydration fill the pores that exist in the soil. The result shows that, the highest compressive strength of 4.6 MPa was obtained by Nopa soil at the curing age of 28 day with $12 \%$ cement content and for all soil samples the compressive strength increased as cement stabilizing percentage increases. When compared with result from other studies, a research work has shown an achievement of a maximum compressive strength of $3.78 \mathrm{MPa}$ for 28 days curing age with $12 \%$ cement stabilization ${ }^{[6]}$, meanwhile in a different research, the researcher had achieved a maximum compressive strength of $3.5 \mathrm{MPa}$ for 28 days curing age with $15 \%$ cement stabilization ${ }^{[7]}$. Lastly a maximum compressive strength of $2.78 \mathrm{MPa}$ result was reported in a study of ${ }^{[8]}$, for 28 days with $15 \%$ cement stabilization which also had a lower strength when compared with the result of $12 \%$ cement stabilization achieved in this study.

\subsection{Effect of Cement Content on Water Absorp- tion of HFBs}

Table 3. Mean Water absorption of Hydra form block

\begin{tabular}{cccccc}
\hline & \multicolumn{5}{c}{ Cement Content in (\%) } \\
$\begin{array}{c}\text { 28th Day Mean } \\
\begin{array}{c}\text { Water absorption in } \\
\text { \% }\end{array}\end{array}$ & $0 \%$ & $3 \%$ & $6 \%$ & $9 \%$ & $12 \%$ \\
\cline { 2 - 6 } Mettu & 23.18 & 17.30 & 14.85 & 12.88 & 10.27 \\
& & & & & \\
Gore & - & 22.98 & 16.70 & 14.41 & 12.29 \\
& & & & & \\
Nopa & 21.94 & 16.31 & 12.37 & 11.52 & 9.96 \\
& & & & & \\
Hurumu & - & 17.53 & 14.91 & 12.80 & 11.48 \\
\hline
\end{tabular}

Therefore, all blocks except HFB produced with Gore soil, which was stabilized with cement $(6 \%, 9 \%$, and $12 \%$ ) has water absorption value below $15 \%$ which is within the recommended values $(0-15) \%$ as the ${ }^{[4]}$. HFBs produced with Gore soil with 3 and $6 \%$ cement content are not suitable for a capillary environment therefore can be used only in a dry environment with no risk of being wet.

Absorption capacity of $9.8 \%$ was reported in a study of $^{[9]}$, after 28 days with $12 \%$ cement stabilization which had almost the same result when compared with the result of $12 \%$ cement stabilization achieved in this study.

\subsection{Affordability of Hydra Form Blocks in Com- parison with HCB and Fired Clay Bricks}

The cost of hollow concrete block wall is 195Birr per $\mathrm{m}^{2}$, fired clay brick wall is 201Birr per $\mathrm{m}^{2}$, but one $\mathrm{m}^{2}$ of hydra form block wall is 132.3 Birr per $\mathrm{m}^{2}$ which is $32 \%$ cheaper than Hollow Concrete block walls and 34\% cheaper than Fired clay brick. Therefore, hydra form block is cheapest in terms of production cost.

\subsection{The Possible Job Opportunities Created for the Local Community}

Since the mass production of HFB is labor intensive, it creates different job opportunities for the local people. A typical hydra form block production center can create jobs for more than 50 people.

\section{Conclusions}

Soil from Mettu, Gore, Nopa, and Hurrumu has a good composition of Gravel, Sand and Fine Soil (Silt and Clay) which is suitable to use as a raw material for HF block production. Except Gore soil all have significant characteristics that make it suitable for stabilization with recommended plasticity index. The compressive strength at 28 day age obtained for hydra form blocks were higher than the recommended $1 \mathrm{MPa}$ for masonry unit for all the blocks, except HFB produced with Gore soil. Increase

Table 4. Cost comparison of HFB with Fired Clay Brick and HCB

\begin{tabular}{ccccc}
\hline Item & Unit & Size & No. pcs per m2 of a wall & Price per pcs (Birr) \\
\hline Hollow Concrete Block & Pcs & $40 \times 20 \times 20 \mathrm{~cm}$ & 13 & 15 \\
Fired clay brick & Pcs & $25 \times 12 \times 6 \mathrm{~cm}$ & 67 & 301 \\
HFB & & & 35 & 3.76 \\
\hline
\end{tabular}


in cement content results in an increase in the compressive strength value of blocks made at the same constant compaction pressure. Water absorption was also found to be well within the maximum limit of $15 \%$ allowed for masonry unit for block produced with $6 \%, 9 \%$, and $12 \%$ cement content. For block made without any addition of stabilizer and stabilized with 3\% cement, water absorption result is out of the recommended values $(0-15) \%$ by the standard ${ }^{[4]}$. The cost comparison of Hydra form blocks with hollow concrete block and fired clay brick shows that the hydra form block is cheapest walling material in terms of production cost and a typical hydra form block production center can create jobs for more than 50 people.

\section{Acknowledgement}

We would like to thank almighty God who helped us in all aspects of our life including this work.

We would also like to give thanks to all our friends who gave us their encouragement and support while carrying out this research.

\section{References}

[1] Baba, S. W., Zanna, A. L., Mustapha, M. M. (2013). Properties of Compressed Stabilized Earth Blocks (CSEB) For Low-Cost Housing Construction: International Journal of Sustainable Construction Engineering and Technology. 4 (2).

[2] Kerali, A. G. (2001). Durability of compressed and cement-stabilized. A thesis submitted in partial fulfilment of the requirements for the degree of Doctor of Philosophy in Engineering, University of Warwick.
[3] Montgomery, D. E. (2002). Dynamically-compacted cement stabilized soil blocks for low-cost walling, University of Warwick, School of Engineering.

[4] African Regional Standards, (1998). Compressed Earth Blocks Standards, CDI and CRATerre Publications.

[5] Holmes, S., Rowan, B. (2015). Building with lime and lime stabilized soil. 2nd edition 2014 - 2015. A Manual and Practical Guide for the Selection, Preparation, Testing and Application of Natural Materials for Durable Earth Based Low Cost Construction.

[6] Chimuanya, O. T., Salleh, N. M., Raja, T. A. (2014). Stabilization of compressed earth block using laterite soil. Infrastructure University Kuala Lumpur Research Journal. 2(1).

[7] Ongpeng, J. M. C., Gapuz, E., Roxas, C. L. C. (2017). Optimization of mix proportions of compressed earth blocks with rice straw using artificial neural network. Advance in structural engineering and mechanics (ASEM17). Llano, Korea.

[8] Raheem, A. A., Bello, O.A., Makinde, O.A. (2010). A Comparative Study of Cement and Lime Stabilized Lateritic Interlocking Blocks. The Pacific Journal of Science and Technology. 11(2).

[9] Tadege, A. (2007). Study of compressed cement stabilized soil block as an alternative wall making material. A thesis submitted to The Schools of Graduate Studies of Addis Ababa University in partial fulfillment of the requirements for the Degree of Master of Science in Construction Technology and Management. 